\title{
EVALUATION OF STRESSES IN LARGE DIAMETER, THIN WALLED PIPING AT SUPPORT LOCATIONS (U)
}

by B. J. Bryan

Westinghouse Savannah River Company

Savannah River Site

Aiken, South Carolina 29808

Other Authors:

H. E. Flanders, Jr. (WSRC)

G. B. Rawls, Jr. (WSRC)

A paper proposed for Presentation/Publication at/in the ASME PVP Conference

Denver, CO

07/25-29/93

This paper was prepared in connection with work done under Contract No. DE-AC09-89SR18035 with the U. S. Department of Energy. By acceptance of this paper, the publisher and/or recipient acknowledges the U. S. Government's right to retain a nonexclusive, royalty-free license in and to any copyright covering this paper, along with the right to reproduce and to authorize others to reproduce all or part of the copyrighted paper. 


\section{DISCLAIMER}

This report was prepared as an account of work sponsored by an agency of the United States Government. Neither the United States Government nor any agency thereof, nor any of their employees, makes any warranty, express or implied, or assumes any legal liability or responsibility for the accuracy, completeness, or usefulness of any information, apparatus, product, or process disclosed, or represents that its use would not infringe privately owned rights. Reference herein to any specific commercial product, process, or service by trade name, trademark, manufacturer, or otherwise does not necessarily constitute or imply its endorsement, recommendation, or favoring by the United States Government or any agency thereof. The views and opinions of authors expressed herein do not necessarily state or reflect those of the United States Government or any agency thereof.

This report has been reproduced directly from the best available copy.

Available to DOE and DOE contractors from the Office of Scientific and Technical Information, P.O. Box 62, Oak Ridge, TN 37831; prices available from (615) 576-8401, FTS 626-8401.

Available to the public from the National Technical Information Service, U.S. Department of Commerce, 5285 Port Royal Rd., Springfield, VA 22161. 


\title{
EVALUATION OF STRESSES IN LARGE DIAMETER, THIN WALLED PIPING AT SUPPORT LOCATIONS (U)
}

\author{
BJ Bryan, H.E. Flanders, Jr., and G.B. Rawls, Jr. \\ Savannah River Site \\ Westinghouse Savannah River Company \\ Aiken, South Carolina
}

\section{ABSTRACT}

The highest stresses in many thin walled piping systems are the local stresses at the pipe supports. These secondary stresses are caused by saddles or other structural discontinuities that restrain pipe ovalization. A static analysis of a thin walled pipe supported on structural steel saddle under dead weight loading is presented herein.

The finite element analysis is performed using a shell model with distributed gravity and hydrostatic pressure loading. Parametric studies on global and local stress are performed to determine the effect of the pipe diameter to thickness ratio. Two aspects of the saddle design are also investigated: the effect of saddle width, and the effect of saddle wrap angle. Additionally, the computed stresses are compared to closed form solutions.

\section{INTRODUCTION}

This paper was developed from an analysis of a large diameter thin wall cooling water piping system that is supported on saddle type supports. Figure 1 shows a typical saddle support. The evaluation includes both stress analysis and a review of the applicability of current design codes. The stress analysis shows that ovalization of the pipe cross-section contributed to large stress intensity for both global and local stresses. The ovalization was determined to be an effect of the large diameter to wall thickness ratio $(D / t)$. The values of $D / t$ ratio for the cooling water piping were greater than 100 .

Comparison of current design codes such as ASME Boilet \& Pressure Vessel Code [1], and ANSI/ASME B31.1 [2] demonstrate that these codes were generally limited to $D / t$ ratios of less than 100. However, the ASME B\&PV Code provides the most comprehensive treatment for local stress evaluation. The AWWA Code [3] was reviewed, since it is applicable to large D/t ratios. The AWWA M11 Manual provides a methodology for calculating localized stress at saddle type supports. AWWA also states that the stress intensity is practically independent of the width of the saddle support. The saddle width is Dimension $\mathrm{b}$ in Figure 2.

Figure 1 - Pipe on Saddle Support

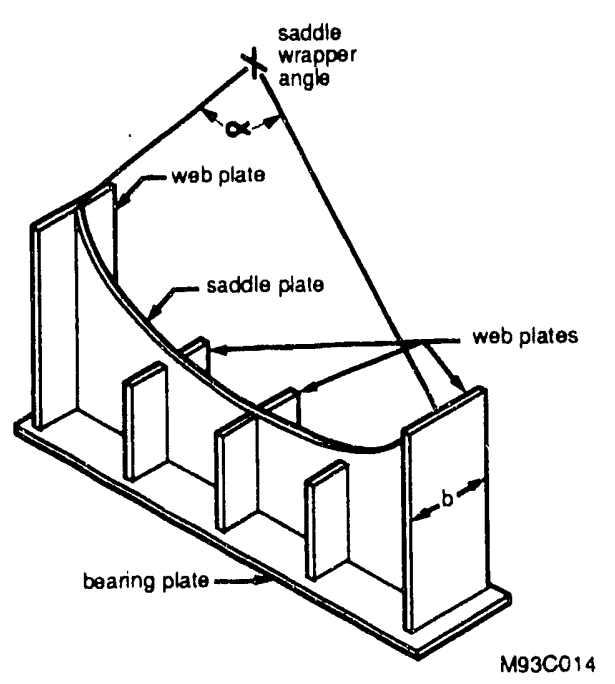

Figure 2 - Typical Saddle Suppont 
Three different aspects of analyzing piping with large diameter to wall thickness ratio are evaluated in this paper. The data presented is for $D / t$ ratios between 50 and 400 . All the analyses were performed for piping on saddle supports. The following areas were evaluated:

- The effect of ovalizati in on the global bending stress in the piping as compared to beam theory.

- The effect of ovalization on the local stress at a saddle type support, including the methodology for classification and calculation of the local stress.

- The effect of saddle support design parameters on local stress.

\section{ANALYSIS}

The global stress state is calculated using both the finite element method and beam theory. The local stress state is calculated using both the finite element method and the AWWA method. For consistency, all the analyses documented in this paper use elastic methods and are on a pipe configuration with a nominal $60 \mathrm{in}$. diameter and $80 \mathrm{ft}$ span length. The basis for the finite element and AWWA analyses is discussed below.

\section{Einite Element Method}

The analysis is performed using the ABAQUS finite element code [4]. Figure 3 shows that the model is a full cylindrical section comprised of shell elements. The model is subjected to dead weight loading, which is composed of hydrostatic pressure inside the pipe and gravity on the steel pipe wall. Since internal pressure would tend to stabilize ovalization, it is not included in the model. The coordinate system is defined as:

\section{$x$ - Horizontal; Transverse to Pipe Axis $y$ - Horizontal; Longitudinal Pipe Axis $z$ - Vertical}

The pipe wall is modeled with shell elements, ABAQUS element type S8R5. This is a second order, eight node quadrilateral element with five degrees of freedom per node that can react both membrane and bending loads. The element has four integration points on the surface and three integration points through the thickness of the shell at each surface point

Each element spans a $6^{\circ}$ are in the circumferential direction for a 3.14" element length. The element length in the longitudinal direction is 3 " for a distance of 18 " from the center line of the vertical support, and is increased to $5.37^{\prime \prime}$ for the remaining length of the pipe. This produces a more refined mesh in the region of the structure where the stress gradients are large.

The thickness of the elements in the region of the supports is modeled as the sum of the pipe wall thickness and the saddle wrapper thickness. Since the saddle wrapper is welded to the pipe wall, they are modeled as one thickness.

The pipe model boundary conditions make use of symmetry. The model extends from the center line of the saddle to the mid. span point, halfway between two siddles. The nodes at both ends of the model are constrained with $y$ - Symmetrical boundary conditions (which are $u_{y}=r_{x}=r_{z}=0$ ).

Additional boundary conditions are applied to the saddle support structure specified in two parts (Figure 1). The nodes that represent the saddle plate on the centerline of the support are constrained in the vertical and both horizontal directions $\left(u_{x}=u_{y}=u_{z}=0\right)$. The nodes which represent the web plates are constrained in the vertical and longitudinal directions $\left(u_{y}=u_{z}=0\right)$.
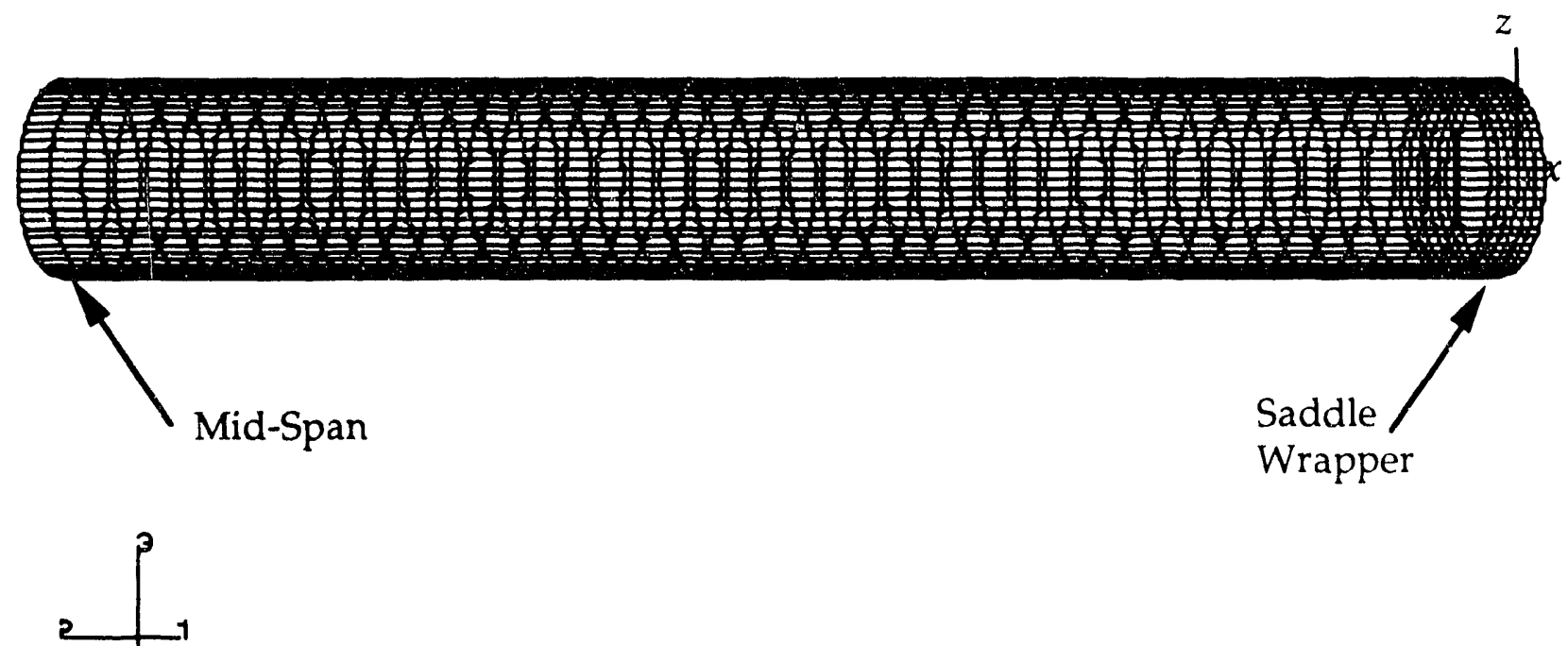

Figure 3 - Finite Element Mode! 


\section{AWWA Method}

Pipe stresses in the area adjacent to the saddle support are calculated in accordance with the method outlined in the American Water Works Association publication, Steel Pipe - A Guide for Design and Installation, Reference [3]. For a pipe that fits well with the saddle, the maximum localized pipe stresses are predicted not to exceed the stresses given by Equation $\{1\}$.

$$
\begin{array}{ll}
S_{\ell}=k \frac{P}{r^{2}}=\ln \left(\frac{R}{t}\right) \\
\text { where: } \quad S_{\ell}=\text { Localized stress (psi) } \\
P=\text { total saddle reaction (lb) } \\
R=\text { pipe radius (in.) } \\
t=\text { pipe wall thickness (in.) } \\
k=\left[0.02-0.00012\left(\alpha=90^{\circ}\right)\right]=\text { saddle } \\
\text { coefficient (unitless) } \\
\alpha=\text { total saddle wrap angle }\left(^{\circ}\right)
\end{array}
$$

Other stresses must be added to the localized stress to produce the total stress. These stresses are listed below.

$$
\begin{aligned}
& S_{f}=\text { flexure stress in pipe span } \\
& S_{p}=\text { hoop stress due to internal pressure }
\end{aligned}
$$

Then the total stress in the pipe is as follows:

$$
S_{\text {tolal }}=S_{\ell}+S_{f}+S_{p}
$$

Since internal pressure would tend to stabilize ovalization, it is not included in the analysis $\left(S_{p}=0\right)$.

\section{Acceptance Criteria}

The effect of pipe support loads on the pipe wall has been the subject of early studies in piping design. The Kellogg manual, Design of Piping Systems, [5] (1955) suggests the following:

"When such local stresses are evaluated they should be treated in the category of secondary or localized stresses ... the allowable limit for such stresses when due to sustained loading cannot reasonably be set at the limit for sustained primary stress $S_{h}$; instead it is recommended that a limit of $2 S_{h}$ be used for design purposes."

The pipe stress due to contact load is typically calculated based on solutions such as Formulas for Stress and Strain by R.J. Roark and W.C. Young [6] or WRC Bulletins. The Roark formula for contact stresses is adopted by the American Water Works Association (AWWA) Steel Pipe - A Guide for Design and Installation (Manual M11) [3]. The AWWA manual states that "the ability of steel pipe to resist saddle load has sometimes been greatly underestimated by designers" and, consistent with Roark, recommends an allowable of $2 S_{y}$ for the maximum localized stress at the saddle.

The position of the Nuclear Industry on contact stress is provided in ASME Section III of the Boiler and Pressure Vessel Code [1]. The ASME Nuclear position is important since the Nuclear Industry has provided the largest volume of work on evaluating local stress. Section III Subsection is NB, NC and ND address the question of interaction between the pressure boundary and its attachments. The code requires that the interaction effects of attachments on the pressure boundary producing localized bending stresses be considered by the piping designer.

The ASME Code also provides the most comprehensive treatment of classification of stresses. Table 1 shows the evaluation that determines the stress classification. The local stress at a saddle support is classified as a secondary stress. The criteria in NC 3217.1 for secondary stress, which refers to Appendix XIII [7], provides limits of secondary stress for Class 2 components. The local stress limit of XIII-1145 for primary plus secondary stress intensity is $3 S_{m}$

In conclusion, a review of current acceptance criteria points to a $2 S_{y}$ or $3 S_{m}$ allowable for the evaluation of local stress. Since $2 S_{y}$ is approximately equal to $3 S_{m}$ for most steels, the different industrial standards are consistent. However, the stress should not be allowed to exceed $S_{u}$.

\section{Classification of Stress}

Appendix XIII-1000 [7] classifies a secondary stress as a stress developed by self constraint of a structure. Bending stress at a gross structural discontinuity is given in Appendix XIII as an example of a secondary stress. A gross structural discontinuity is a geometric structural discontinuity that effects the stress distribution through the entire wall thickness.

The calculation below shows that the largest contributor to the local pipe stress at the saddle supports is through wall bending. Therefore, the local stress limit of $3 S_{m}$ was used for an acceptance criterion. Table 1 shows a representative through wall stress distribution for the pipe near the saddle support.

\begin{tabular}{|c|r|r|r|}
\hline \multirow{2}{*}{ Surface } & \multicolumn{3}{|c|}{ Stress Components (psi) } \\
\cline { 2 - 4 } & Hoop $\left(\sigma_{11}\right)$ & Axial $\left(\sigma_{22}\right)$ & Shear $\left(\sigma_{12}\right)$ \\
\hline Outside & $-111,400$ & $-83,900$ & 21,500 \\
Mid-plane & $-10,900$ & $-22,200$ & 10,000 \\
Inside & 89,900 & 39,500 & 1,500 \\
\hline
\end{tabular}

Table 1 - Through Wall Stress Distribution

The bending stress component is determined by subtracting the mid-plane (membrane) stress from the stress at the outside and inside surfaces. The bending stress components are shown in Table 2 .

\begin{tabular}{|l|r|r|r|}
\hline \multirow{2}{*}{ Surface } & \multicolumn{3}{|c|}{ Bending Stress Components (psi) } \\
\cline { 2 - 4 } & Hoop $\left(\sigma_{11}\right)$ & Axial $\left(\sigma_{22}\right)$ & Shear $\left(\sigma_{12}\right)$ \\
\hline Out - Mid & $-100,500$ & $-61,700$ & 11,500 \\
In - Mid & 100,800 & 61,700 & $-11,500$ \\
\hline
\end{tabular}

Table 2 - Through Wall Bending Stress

A review of the data in Tables $l$ and 2 shows that the local stress is largely through wall bending (secondary stress) and the $3 S_{m}$ limit for primary plus secondary stress applies.

The design stress intensity $\left(S_{m}\right)$ is determined from ASME Article III-2000 [8]. 


$$
S_{m}=\min \left(\frac{1}{3} S_{w}, \frac{2}{3} S_{y}\right)
$$

For A53 Grade B, a commonly used steel

$S_{y}=35,000$ psi and $S_{u}=60,000$ psi, therefore,

$S_{m}=20,000$ psi and $3 S_{m}=S_{u}=60,000$ psi is the primary plus secondary stress intensity allowable.

\section{RESULTS}

The results of the analyses are categorized as either global or local stresses.

Global_Stresces_The finite element model described above was used to calculate the maximum bending stress at mid-span of the shell model. The bending stress for the mid-span of the finite element analysis (FEA) model were then compared to classical beam theory where the maximum bending stress was calculated at mid-span using the flexure formula:

$\sigma_{\text {Max }}=\frac{M c}{I}$

The moment at mid-span for use with the beam theory was calculated from the beam formula for fixed-fixed end conditions with a uniformly distributed load. These conditions match the boundary and loading conditions of the finite element model. The equation for the moment at mid-span is given below.

$$
M_{\text {midspan }}=\frac{W \ell^{2}}{24}
$$

Figure 4 shows the comparison between the global bending stress calculated using the finite element model and beam theory.

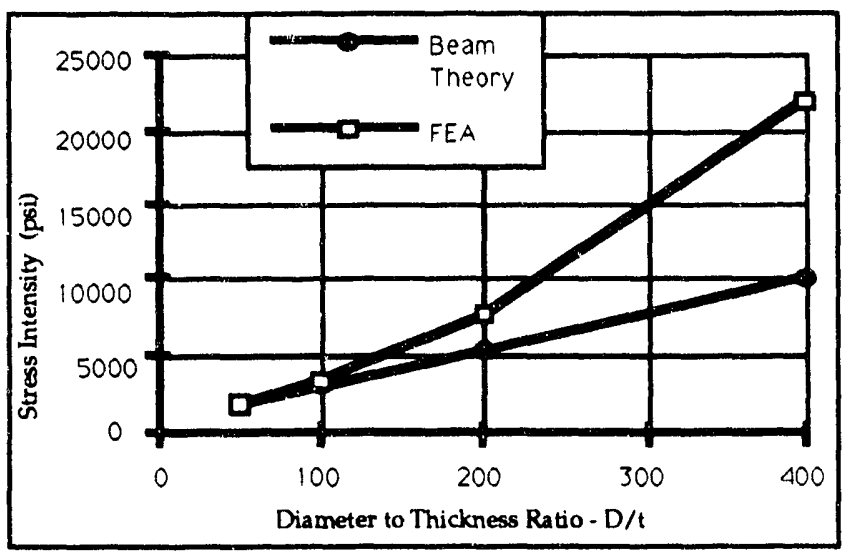

Figure 4 - Global Pipe Stress as a Function of $D / t$

The data is in good agreement for values of $D / t$ less than 100 . When the values of $D / t$ exceed 100 , the difference between stresses produced using beam theory and the shell model increase. There is a $44 \%$ increase in stress above the beam theory stress for a $D / t=200$ and a $119 \%$ increase in stress above beam theory for a $D / t=400$. In all the cases, the reaction forces calculated using beam theory and the finite element method were comparable.

\section{Local Stresses}

The finite element analysis investigates the effect of three aspects of the pipe and saddle structure on the localized stresses.
The diameter to thickness ratio is varied from 50 to $4(k)$. The saddle wrapper angle is varied from $72^{\circ}$ to $168^{\circ}$. The saddle width is varied from $0.4 D$ to 0 for a line contact support.

The AWWA [3] method was used to investigate two aspects of the pipe and saddle structure on the localized stresses. The diameter to thickness ratio of the pipe and the saddle wrap angle were varied the same as in the finite element analysis. The results of the two analysis methods are presented below.

Diameter to Thickness $(D / t)$ Ratio. For this investigation the diameter $(D)$, saddle wrap angle $(\alpha)$, and saddle width $(b)$ were held constant at $60 \mathrm{in} ., 120^{\circ}$, and $0.4 D$ respectively. The thickness was varied so as to yield $D / t$ ratios of $50,100,150$, 200,300 , and 400 . The highest stresses occur at the top outside corner of the saddle. The stress intensity as a function of the D/t ratio is plotted in Figure 5 for both the finite element (FEA) and AWWA methods.

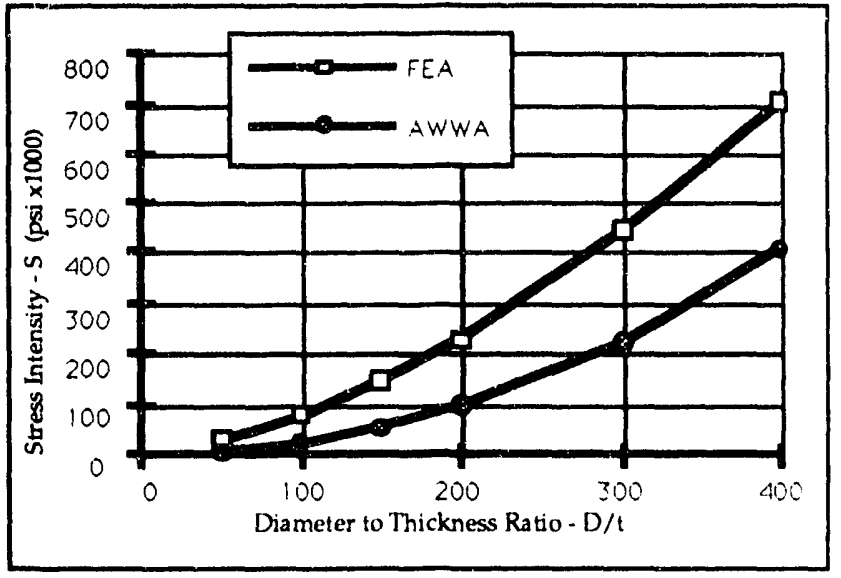

Figure 5 - Local Pipe Stress as a function of $D / t$ Ratio

As can be seen in Figure 5, the D/t ratio has a dramatic effect on the stress intensity. $S$. Doubling the $D / t$ ratio from 50 to 100 causes $S$ to increase by a factor of 2.8 for the FEA and 3.9 for the AWWA method. Doubling D/t from 200 to 400 causes $S$ to increase by a factor of 3.1 for the FEA and 4.3 for the AWWA method. The FEA method consistently predicts significantly higher stresses than the AWWA method.

Saddle Wran Angle $(\alpha)$. In order to investigate the effect of saddle wrap angle, the pipe diameter $(D)$ and thickness $(t)$ and saddle width $(b)$ were held constant at 60 in., 0.6 in., and 24 in. respectively $(D / t=100)$. The saddle wrap angle $(\alpha)$ was varied from $72^{\circ}$ to $168^{\circ}$ in $24^{\circ}$ increments. The stress intensity as a function of $\alpha$ is plotted in Figure 6 for both the FEA and AWWA methods. 


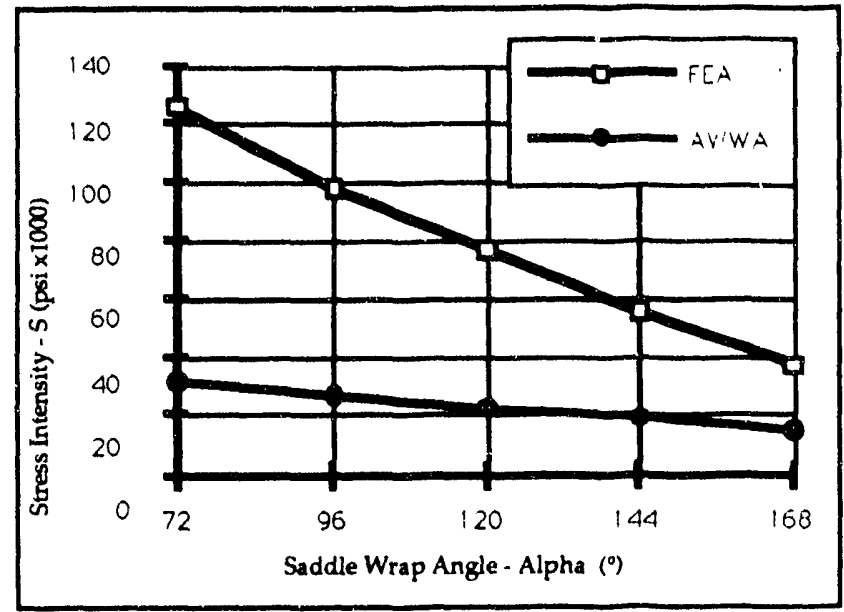

Figure 6 - Local Pipe Stress as a function of saddle wrap angle, $\alpha$

Figure 6 from Equation $\{1\}$ shows that the stress intensity, $S$, calculated using the AWWA method is a linear function of the saddle wrap angle, $\alpha$. Furthermore, Figure 6 shows that the FEA method also predicts a relationship between $S$ and $\alpha$, which is close to linear. The FEA predicts significantly higher stresses than the AWWA method.

Saddle Width (b). In order to investigate the effect of saddle width, the pipe diameter $(D)$ and thickness $(t)$ and saddle wrap angle $(\alpha)$ were held constant at 60 in., 0.3 in., and $120^{\circ}$ respectively $(D / t=200)$. The saddle width $(b)$ was varied from $40 \%$ of the diameter to a line contact in $0.1 D$ increments. The stress intensity from the FEA as a function of b/D is plotted in Figure 7. The AWWA [3] states that the stress is practically independent of the saddle width.

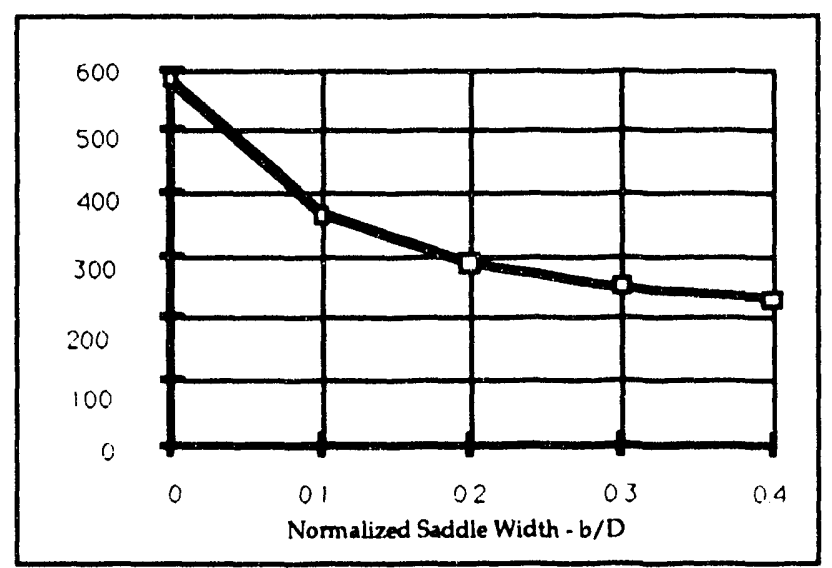

Figure 7 - Pipe Stress as a Function of Saddle Width Ratio, $b / D$

As can be seen in Figure 7, the FEA results show that the $b / D$ ratio has a strong effect on the maximum stress intensity, $S$. Decreasing the saddle width from $0.1 D$ to a line contact increases $S$ by a factor of 1.6. However, increasing the saddle width from $0.3 D$ to $0.4 D$ only decreases $S$ by a factor of 1.1 . Thus, for a small $b / D$ ratio the maximum stress intensity is very sensitive to change in saddle width. For a large $b / D$ ratio, the stress intensity is not sensitive to change in saddle width.
Therefore, the premise stated by AWWA $|3|$ is valid for $b / D$ ratios of 0.3 and greater.

\section{CONCLUSION}

Review of the deadweight stresses produced by the analyses described herein leads to the following conclusions:

- Global stresses in piping can be predicted accurately using beam theory for values of $D / 1$ less than 100 . For values of $D / t$ greater than 100 , shell theory must be used to calculate stresses and to account for distortion of the cross section.

- For thin walled pipe, D/t greater than 100 , the local stresses due to through wall bending at the pipe supports dominate the state of stress.

- For large saddle widths, b/D greater than 0.3, the local stresses due to pipe supports are independent of saddle width. However, for small saddle widths the local stresses increase rapidly with decreasing saddle width.

- The finite element method consistently predicts higher local stress than the AWWA method.

\section{ACKNOWLEDGMENT}

This paper was prepared in connection with work done under contract No. DE-AC09-89SR 18035 with the United States Department of Energy.

\section{REFERENCES}

[1] ASME Boiler and Pressure Vessel Code, Section III, Rules for Construction of Nuclear Power Plant Components, American Sociely of Mechanical Engineers, New York, 1989

[2] ANSI/ASME B31.1, Power Piping, American Sociely of Mechanical Engineers, New York, 1986

[3] AWWA Manual MII. Steel Pipe - A Guide for Design and Installation, American Water Works Association, 1989

[4] Hibbitt, Karlsson, and Sorensen, Inc., ABAQUS Users' Manual, Version 4.9. Pawtucket, Rhode Island, 1991

[5] The M. W. Kellogg Company, Design of Piping Systems, Revised Second Edition, John Wiley and Sons, Inc., 1956

[6] Roark, R.J., and Young, W.C., Formulas for Stress and Strain, $4^{\text {th }}$ Edition, McGraw-Hill, New York, 1965

[7] ASME Boiler and Pressure Vessel Code. Section III, Appendix XIII, Design Based on Stress Analysis, American Society of Mechanical Engineers, New York, 1989 

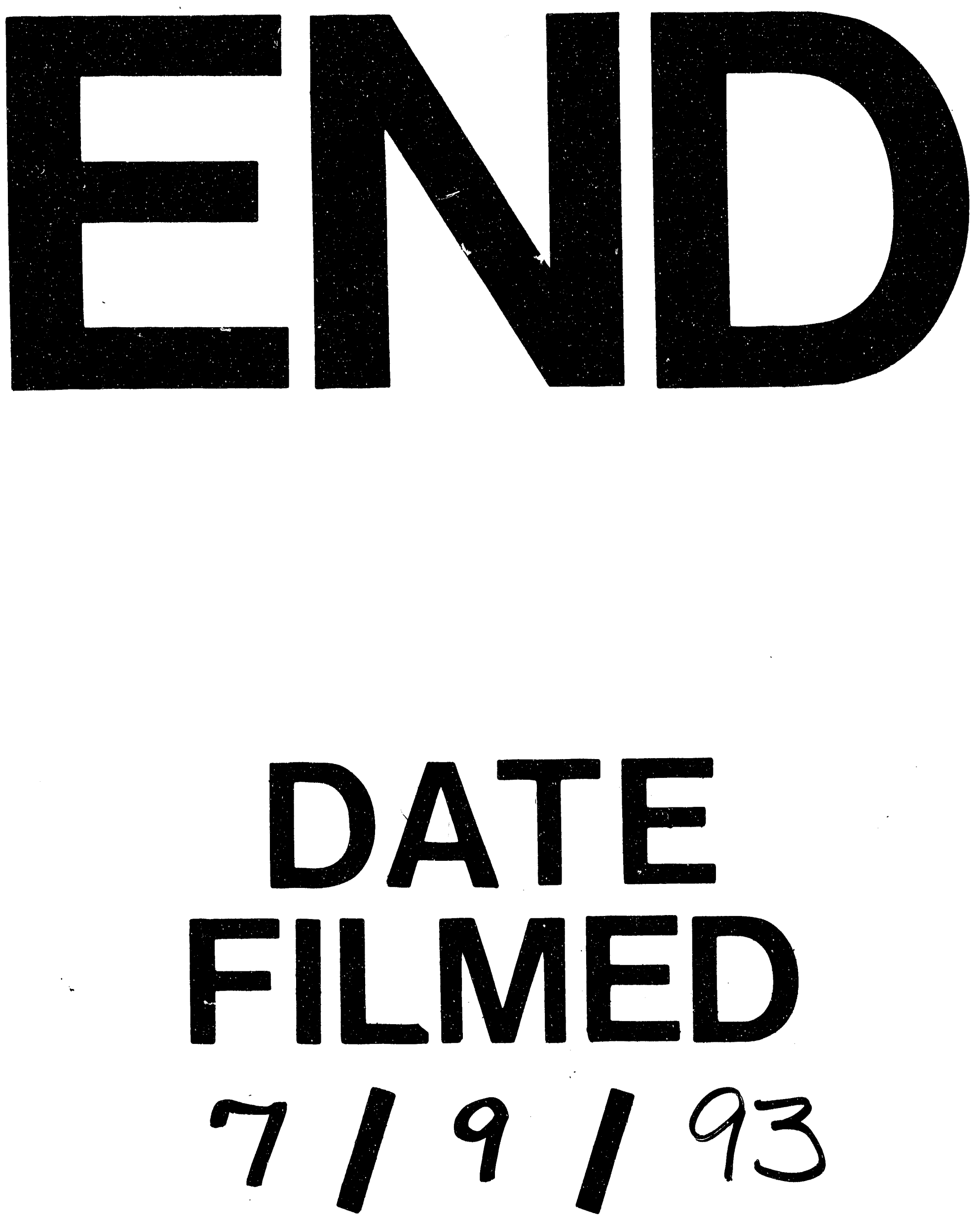

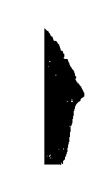


